\title{
Armadilha de sedimentos aplicada ao lago do Parque Joaquim Teodoro de Oliveira de Campo Mourão/PR
}

Atualmente, o lago do Parque Municipal Joaquim Teodoro de Oliveira da cidade de Campo Mourão no estado do Paraná corre sério risco de extinção devido ao assoreamento, em consequência do transporte e deposição de sedimentos, característicos por causar problemas como redução do volume de cursos d'água e bloqueio de tomadas de água e comportas. O processo de assoreamento é natural, basicamente causado pelo represamento do rio devido às erosões e deposições de sedimentos. Além disto, a urbanização tem avançado bastante nos últimos anos e aumentado a quantidade de materiais oriundos de construção (como a areia) nas águas pluviais, que têm o lago como destino. Existem alternativas de medidas preventivas a serem tomadas no sentido de lidar com este tipo de problema, como a dragagem, uma medida paliativa que consiste na retirada do assoreamento de um local de modo a aprofundá-lo neste ponto, de modo a fazer com que, devido à erosão marginal, o lago assoreie novamente em outra área. Neste sentido, observa-se a necessidade e a importância de desenvolver uma medida mais eficaz para tratar de problemas de assoreamento. Portanto, este trabalho consiste no projeto construtivo de uma armadilha de sedimentos aplicada ao lago em questão, além da proposta de desvio dos sedimentos recuperados pela armadilha por meio de um sistema aberto e canalizado.

Palavras-chave: Transporte de Sedimentos; Assoreamento; Armadilha de Sedimentos.

\section{Sediment trap applied to the lake of Park Joaquim Teodoro Oliveira de Campo Mourão/PR}

\begin{abstract}
Currently, the lake in the Municipal Park Joaquim Teodoro de Oliveira in the city of Campo Mourão in the state of Paraná is at serious risk of extinction due to silting, as a result of the transport and deposition of sediments, which, typically, cause problems such as reduced volume of streams. Water and blocking water intakes and floodgates. The silting process is natural, basically caused by the damming of the river due to erosion and sediment deposition. In addition, urbanization has advanced considerably in recent years and has increased the amount of construction materials (such as sand) in rainwater, which have the lake as a destination. There are alternative preventive measures to be taken in order to deal with this type of problem, such as dredging, a palliative measure that consists of removing silting from a place in order to deepen it in this point, in order to make, due to marginal erosion, the lake again silts up in another area. In this sense, there is a need and importance to develop a more effective measure to deal with silting problems. Therefore, this paper consists of the constructive design of a sediment trap applied to the lake in question, in addition to the proposal to deviate the sediments recovered by the trap through an open and channeled system.
\end{abstract}

Keywords: Sediment Transport; Silting up; Sediment Trap.

Topic: Engenharia de Recursos Hídricos

Reviewed anonymously in the process of blind peer.
Received: 10/07/2020

Approved: $20 / 10 / 2020$
Sabrina Aguiar da Silva (iD)

Universidade Tecnológica Federal do Paraná, Brasil http://lattes.cnpq.br/2605942096595882 http://orcid.org/0000-0003-3797-8128

aguiarsabrina7@gmail.com

Bianca Mendonça Rodrigues (iD)

Universidade Tecnológica Federal do Paraná, Brasil

http://lattes.cnpq.br/7646749673405938

http://orcid.org/0000-0003-3576-541X

bianca.mr@hotmail.com

Flávia Aparecida Reitz Cardoso (10)

Universidade Tecnológica Federal do Paraná, Brasil

http://lattes.cnpq.br/2663975071704461

http://orcid.org/0000-0002-0432-9191

flaviareitz@gmail.com
Helton Rogério Mazzer (iD

Universidade Tecnológica Federal do Paraná, Brasi

http://lattes.cnpq.br/2242190889500017

http://orcid.org/0000-0001-8616-5735

hmazzer@gmail.com

\section{Eudes José Arantes (10)}

Universidade Tecnológica Federal do Paraná, Brasil

http://lattes.cnpq.br/5368039952110556

http://orcid.org/0000-0002-7684-3069

eudesarantes@utfpr.edu.br
Referencing this:

SILVA, S. A.; RODRIGUES, B. M.; CARDOSO, F. A. R.; MAZZER, H. R.; ARANTES, E. J.. Armadilha de sedimentos aplicada ao lago do Parque Joaquim Teodoro de Oliveira de Campo Mourão/PR. Natural Resources, v.10, n.3, p.87-102, 2020. DOI: http://doi.org/10.6008/CBPC2237-9290.2020.003.0010 


\section{INTRODUÇÃO}

O assoreamento é o responsável pela diminuição do volume de água de reservatórios e consequente redução da capacidade de geração de energia. Sua principal causa é o transporte de sedimentos pela água da chuva, que pode ser originado pelo solo exposto devido à retirada da vegetação e esgotamento do mesmo pelo uso inadequado. Todos os reservatórios estão fadados a ter a sua capacidade de armazenamento parcial ou totalmente tomada pelos sedimentos, e assorearem. Portanto, a análise do processo de assoreamento deve fazer parte das atividades dos projetos de construção e manutenção, sendo indispensável uma correta colocação dos órgãos de tomada de água, para prevenir eventuais dificuldades de operação, ou mesmo de interrupções no aprovisionamento da água (CABRAL, 2005).

Conforme explicitado, observa-se a necessidade de técnicas para impedir ou ao menos conter o avanço do processo de assoreamento de reservatórios. Shen et al. (1996) apontam algumas destas medidas: Promover a diminuição da quantidade final de sedimentos que entra no reservatório por meio do controle da erosão da bacia e da retenção de sedimentos; Remover os sedimentos de forma mecânica, por meio de dragagens; Permitir a passagem do escoamento carregado de sedimentos pelo reservatório e fazer a liberação por descarga de fundo localizada na barragem. Paralela a estas soluções, existe o método da implantação de uma armadilha de sedimentos no reservatório em processo de sedimentação e consequente assoreamento.

Atualmente existem poucos estudos que consistem no desenvolvimento (numérico, experimental ou aplicado) de armadilhas de sedimentos destinadas à contenção de sedimentos em reservatórios, no entanto, conforme Souza (2006), os resultados obtidos em sua tese comprovam a eficiência da captação de sedimentos por meio de armadilhas de sedimentos, modeladas tanto numericamente quanto experimentalmente.

Este trabalho tem como objetivo propor uma alternativa para impedir a evolução do assoreamento do lago do Parque Joaquim Teodoro de Oliveira de Campo Mourão - Paraná por meio do desenvolvimento do projeto construtivo de uma armadilha de sedimentos com locação da canalização aberta dos sedimentos armazenados e da definição do ponto de descarte final dos mesmos.

\section{METODOLOGIA}

De acordo com o IBGE (2019), o município de Campo Mourão localiza-se no Centro Oeste do estado do Paraná. Com uma área de 759,107 km² situa-se entre os municípios de Cianorte, Goioerê, Cascavel e Maringá e possui população de aproximadamente 94.859 habitantes. O clima predominante é o subtropical, a temperatura média é de 20,5 graus Celsius e encontra-se vegetações de cerrado, floresta ombrófila mista e estacional semidecidual no município. A Figura 2 apresenta a localização do parque Joaquim Teodoro de Oliveira localizado no município de Campo Mourão, Paraná. O rio que abastece o lago, conforme é possível observar por meio da figura, é o rio do Campo. 


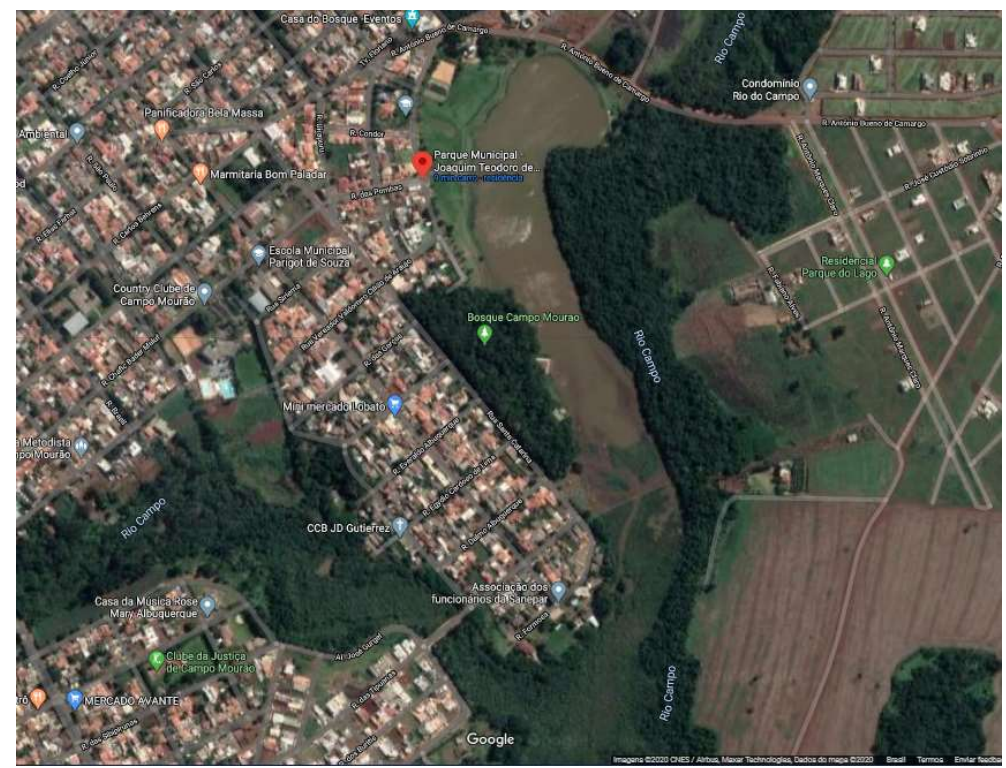

Figura 2: Mapa do lago do Parque Joaquim Teodoro de Oliveira, Campo Mourão/PR. Fonte: Google Maps (2020).

Para realizar o dimensionamento de todos os elementos que compõem uma armadilha de sedimentos é necessário dispor dos dados de vazão (média e máxima) da bacia que abastece o lago, neste caso em específico, a bacia do rio do campo.

Por meio do trabalho desenvolvido por Umeki (2012) que aborda o transporte de sedimentos na bacia hidrográfica do rio do Campo, foi possível determinar a área desta bacia, igual a 115,93 $\mathrm{Km}^{2}$ (CARNEIRO et al., 2010). Analogamente à área total do município, a agropecuária é predominante no uso e ocupação do solo na bacia hidrográfica do rio do Campo (UMEKI, 2012).

\section{Vazão média da bacia}

Pretzel (2017) elaborou o gráfico da curva de permanência com as vazões mínimas e médias, conforme suas respectivas probabilidades. A curva é apresenta na Figura 3.

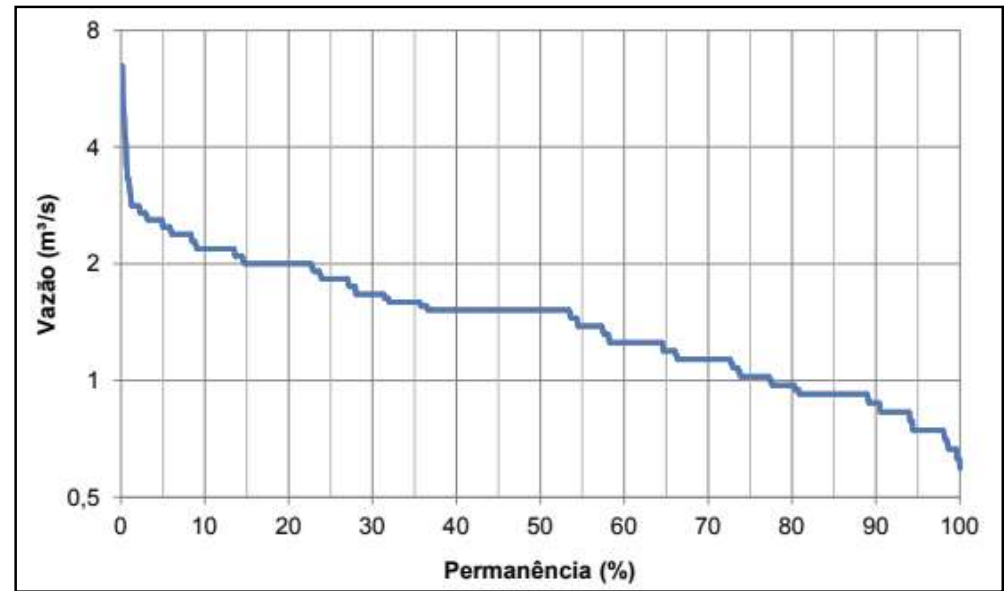

Figura 3: Gráfico da curva de permanência do Rio do Campo. Fonte: Pretzel (2017).

Por meio de levantamento das áreas de drenagem da bacia hidrográfica do Rio do Campo (Figura 4) foi possível determinar a área de escoamento do posto fluviométrico, correspondente a $79,72 \mathrm{~km}^{2}$. 


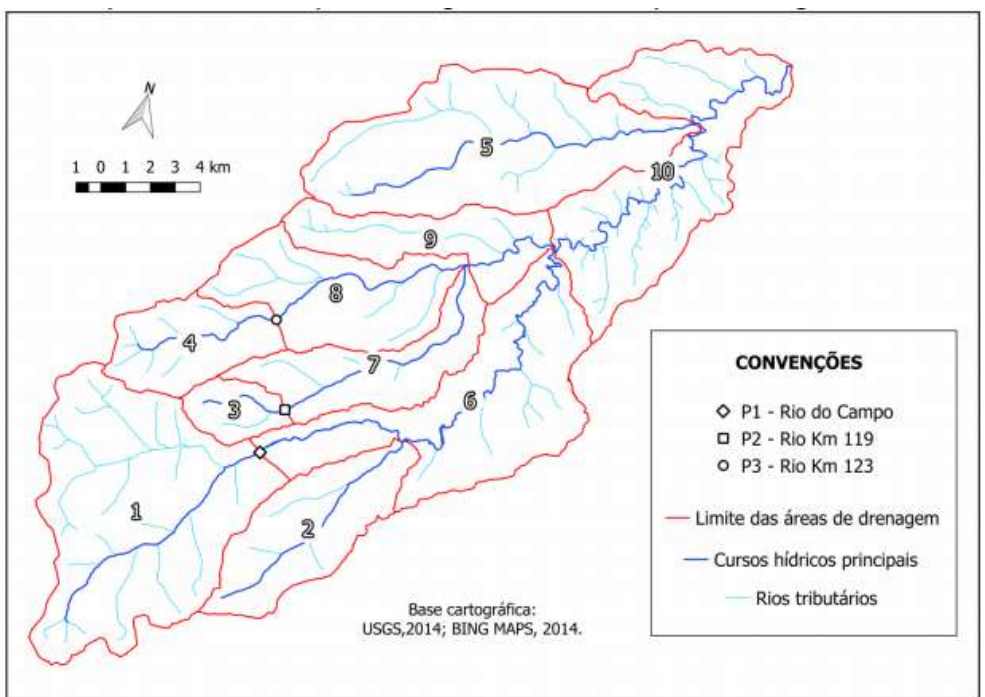

Figura 4: Segmentação da bacia hidrográfica do Rio do Campo em áreas de drenagem. Fonte: Pretzel (2017).

Então, por meio destes dados foi calculada a vazão específica, que alcançou o valor de 0,01905463 $\mathrm{m}^{3} / \mathrm{s} . \mathrm{km}^{2}$ para $\mathrm{Q}_{50}$ (vazão média). Portanto, para determinação da vazão média segundo Pretzel (2017), utiliza-se a Equação 1:

$$
\mathrm{Q} 50=0,01905463 \text {.Área }
$$

Eq. 1

\section{Vazão máxima da bacia}

Para determinação da vazão máxima da bacia hidrográfica do rio do Campo para um período de retorno de 100 anos, utiliza-se a equação 2:

$$
\mathrm{Q}=0,077031 \text {. Área }{ }^{1,283544}
$$

Eq. 2

\section{Projeto Construtivo da Armadilha de Sedimentos}

Para determinar as dimensões da armadilha de sedimentos a ser desenvolvida, primeiramente foi necessário determinar as vazões média e máxima (para um período de retorno de 100 anos), para que assim fosse possível dimensionar a área de captação e o vertedor da armadilha, já que são estes os dois principais elementos construtivos. Após determinadas as dimensões destes elementos, dimensionou-se, proporcionalmente a eles, a armadilha de sedimentos de forma retangular. A seguir serão apresentados os métodos para escolha do posicionamento da armadilha, dimensionamentos de captação e vertedor, inclinação interna para favorecer a deposição dos sedimentos e determinação da periodicidade de descarga dos sedimentos retidos na armadilha. Primeiramente, com relação ao posicionamento da armadilha de sedimentos, objetiva-se dispô-la de modo a captar o máximo de sedimentos oriundos do rio do Campo antes que a água adentre ao lago já assoreado.

Para determinação das alturas e das larguras da entrada (captação) e da saída (vertedor) de água da armadilha é utilizada a vazão média do rio do Campo e a metodologia de Porto (1999) de cálculo de vazão de vertedor com parede delgada. São estabelecidas as mesmas medidas de largura e altura para o canal de captação de água para a armadilha e para o vertedor e calculadas as vazões. Quando a vazão supre a vazão média da bacia do rio do Campo, as medidas de largura (L) e altura (h) são escolhidas para o 
dimensionamento. Por meio da Figura 5 apresenta-se a representação do vertedor de parede delgada e na equação 01 da Tabela 1 tem-se o método de cálculo da vazão neste vertedor. Para o dimensionamento do canal de captação de água foi utilizada a mesma metodologia.

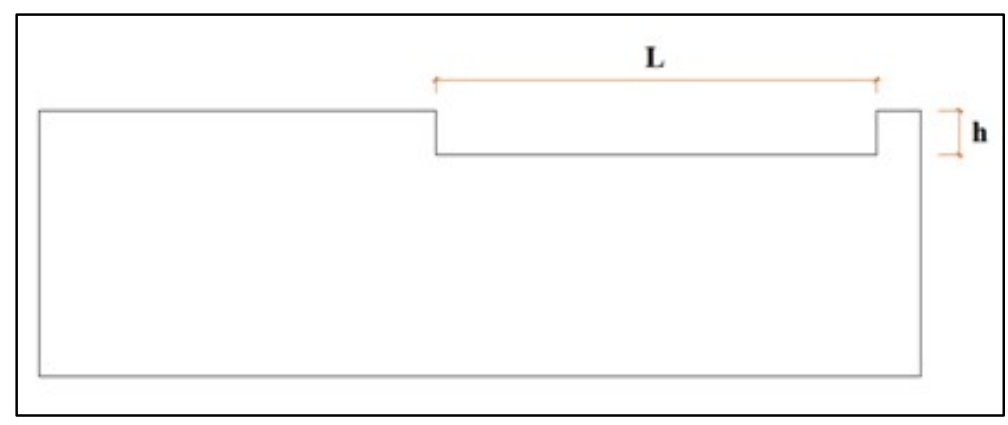

Figura 5: Vertedor de parede delgada.

Optou-se por considerar uma inclinação interna na armadilha que direciona os sedimentos para a canalização de descarga dos mesmos para facilitar e induzir a deposição interna. A representação desta inclinação é apresentada na Figura 6. Esta inclinação é paralela ao canal de captação de água do rio do Campo e ao vertedor da armadilha.

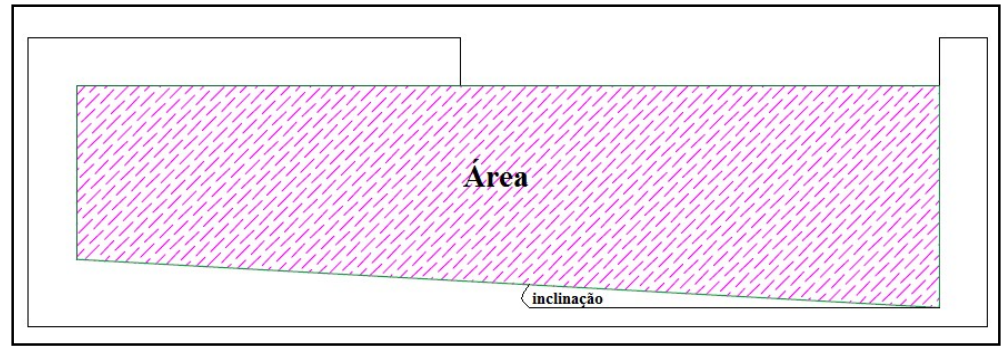

Figura 6: Inclinação interna da armadilha de sedimentos.

Foi utilizada a metodologia de Tsutiya (2006) para dimensionamento de caixas de areia (desarenadores) modificada e adaptada para armadilhas de sedimentos, já que ambas têm o princípio de captar e reter sedimentos de cursos d'água. $\mathrm{O}$ autor apresenta os seguintes critérios de dimensionamento: A velocidade crítica de sedimentação das partículas deve ser igual ou inferior a 0,021m/s; A velocidade de escoamento longitudinal deve ser igual ou inferior a $0,30 \mathrm{~m} / \mathrm{s} ; 0$ comprimento do desarenador, obtido ao aplicarem-se os critérios anteriores, deve ser multiplicado por um coeficiente de segurança de pelo menos 1,5 .

Para o dimensionamento de desarenadores de nível variável devem ser consideradas as condições de operação para os níveis de vazão máxima e mínima. Neste caso, a armadilha de sedimentos será dimensionada para a condição de vazão média e com capacidade de suporte de extravasamento, caso ocorra, eventualmente, a vazão máxima calculada para o período de retorno de 100 anos.

Para o cálculo da área (em planta) da armadilha é necessário conhecer a vazão média de entrada de água carregada com sedimentos na caixa de areia $(\mathrm{Q})$ e a velocidade de sedimentação $\left(\mathrm{V}_{\mathrm{s}}\right)$ destas partículas, que, neste caso, será a velocidade crítica. Para determinar a área necessária à armadilha de sedimentos utiliza-se a equação 2 da Tabela 01. Assim, após determinada a área e como se trata de um caso de 
dimensionamento, primeiramente é considerada uma largura (b) para a armadilha, de modo que o comprimento (L) seja maior que ela e garanta que o formato da armadilha seja retangular ( $L>b)$. Para compensar a turbulência na entrada e na saída da mesma, aplica-se um coeficiente de segurança de $50 \%$ no comprimento $L$ da armadilha. As equações 3 e 4 da Tabela 1 devem ser usadas, respectivamente, para realização destes cálculos. Depois, ajusta-se (somente de forma crescente) estes valores, para facilitar a construção da mesma, para aumentar sua capacidade de armazenamento de sedimentos ou para proporcionar maior segurança caso seja gerado extravasamento da mesma durante o seu período de vida útil.

Já para determinar a profundidade da armadilha, é necessário conhecer a velocidade de escoamento longitudinal (V) e a vazão (Q) para determinar a área transversal da armadilha. Como anteriormente já foi definida a largura (b) da mesma, define-se qual a profundidade necessária para suportar a velocidade de escoamento e a vazão. Como a velocidade de escoamento longitudinal e a área da seção transversal não são conhecidas testa-se uma profundidade arbitrária para a armadilha para determinar a área e verifica-se o critério para velocidade de escoamento longitudinal ( $\mathrm{V} \leq 0,30 \mathrm{~m} / \mathrm{s})$. Após obter a área transversal da armadilha, determina-se a profundidade (h) necessária. As equações necessárias para estes cálculos estão apresentadas na Tabela 1 (equações 5 e 6).

Finalmente, após determinar as três dimensões da armadilha de sedimentos: Largura, comprimento e profundidade, é possível determinar qual o seu volume interno por meio da equação 7 apresentada na Tabela 1. As incógnitas utilizadas nesta equação estão representadas na Figura 7. Para determinação do volume foi utilizada a equação para determinação da área do trapézio retângulo multiplicada pelo comprimento interno da armadilha.

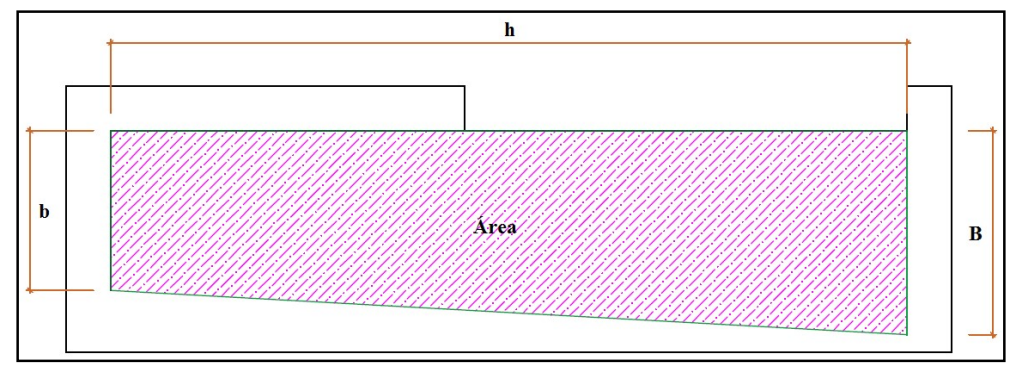

Figura 7: Representação das incógnitas utilizadas para determinar o volume da armadilha.

O trabalho de Umeki (2012) contempla estudos do transporte de sedimentos na bacia hidrográfica do rio do Campo e aborda a quantidade de sedimentos que adentra ao lago, objeto deste estudo. Este resultado apresenta-se na unidade de toneladas ao ano, assim, se fez necessário determinar também o peso específico destes depósitos, apresentado por Carvalho et al. (2000).

Sabendo-se quantas toneladas de sedimentos adentram ao lago ao ano, o peso específico médio destes e o volume interno de armazenamento da armadilha, determina-se quantas vezes ao ano será necessário promover o esvaziamento da armadilha, ao considerar eficiência de captação de $70 \%$ dos sedimentos que chegam à mesma. No entanto, como aqui se trabalha com previsões e estimativas, recomenda-se a instalação de um sensor a ser ativado quando o preenchimento do volume interno estiver 
próximo da capacidade máxima de armazenamento.

O projeto da armadilha de sedimentos desenvolvido neste trabalho conta com um sistema de descarga de sedimentos que deve ser acionado por comporta, ou seja, a descarga deve ocorrer a cada determinado período de tempo e para esta descarga, a armadilha deverá contar com uma canalização conectada a mesma para retirar e destinar estes sedimentos a um canal aberto que se findará em um local propício de descarte, distante do lago, para não agravar ainda mais o problema de assoreamento.

Ao acionar (por meio de abertura da comporta) a descarga dos sedimentos retidos na armadilha, antes de já adentrarem a tubulação e depois ao canal aberto, estes passarão por uma caixa de transição composta por gradeamento para impedir a passagem de materiais grosseiros, flutuantes ou em suspensão, como tronco de árvores, plantas, galhos, etc., normalmente trazidos por cursos de água.

O dimensionamento da abertura na caixa para liberação dos sedimentos também foi feito com base na equação 1 (Tabela 1), enquanto que o dimensionamento das barras que compõem o gradeamento foi feito com base nas recomendações propostas por Tsutiya (2006), que explica que o espaçamento entre barras paralelas deve ser de 7,5 a $15 \mathrm{~cm}$ para a grade grosseira e dispõe dos seguintes tipos de barras de gradeamento (Figura 8).

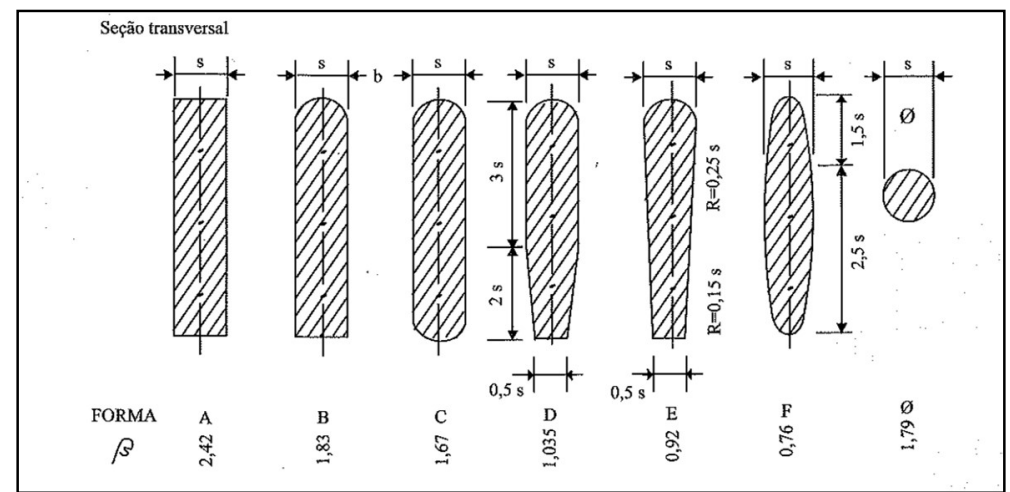

Figura 8: Forma geométrica segundo a seção transversal das barras. Fonte: Tsutiya (2006).

Além disto, o gradeamento acarreta em perda de carga (h). Por meio das equações 8 e 9 apresentadas na Tabela 1, esta perda pode ser calculada. É importante frisar que a incógnita k representa o coeficiente de perda de carga que é adimensional e função dos parâmetros geométricos das grades, $V$ é a velocidade média de aproximação em unidade de $\mathrm{m} / \mathrm{s}$ e g é a aceleração da gravidade, em $\mathrm{m} / \mathrm{s}^{2}$. Para o cálculo do coeficiente $k$ é necessário conhecer $\beta$ (coeficiente, função forma da barra, representado na Figura 8), s (espessura das barras), b (distância livre entre barras) e $\alpha$ (ângulo da grade em relação à horizontal). As barras que constituem as grades devem ser de material anticorrosivo ou protegido por tratamento adequado. Os elementos do gradeamento são apresentados na Figura 9.

Depois de dimensionada a caixa de transição, inicia-se o dimensionamento da tubulação destina os sedimentos da caixa de transição para o canal aberto. Para isto, optou-se por utilizar toda a área da seção transversal da caixa de transição para conectar a tubulação. Assim, o diâmetro externo da tubulação tem a mesma medida da altura (h) da caixa de transição. Além disto, foi verificada a vazão nesta tubulação para determinação do tempo de esvaziamento dos sedimentos da caixa. Primeiramente, para determinar a área 
transversal interna da tubulação, é utilizada a equação 10 (Tabela 1), de determinação da área do círculo e adota-se, neste caso, uma espessura de $10 \mathrm{~cm}$ à tubulação.

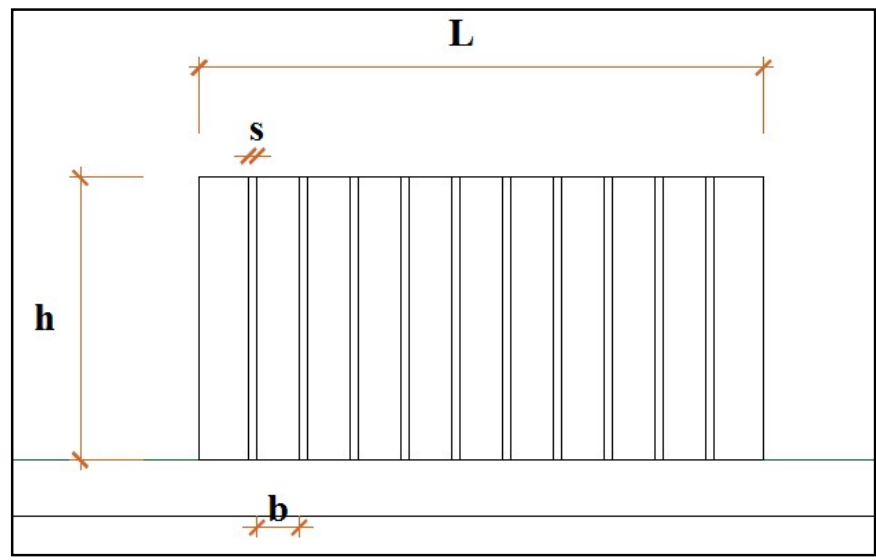

Figura 9: Caixa de transição com gradeamento.

Depois de determinar a área, verifica-se o tempo de esvaziamento da armadilha conforme a vazão na tubulação. Para isto foi utilizada a velocidade média de aproximação dos sedimentos (V) para cálculo da vazão. Esta vazão é determinada por meio da equação 11 também apresentada na Tabela 1. Finalmente verifica-se o tempo total necessário para o esvaziamento da armadilha de sedimentos por meio da equação 12 (Tabela 1).

Para promover o transporte dos sedimentos retidos pela armadilha, propõe-se ao sistema desenvolvido um canal aberto em vala que receberá os sedimentos pela tubulação anteriormente dimensionada. Este canal deverá apresentar diâmetro maior ou igual ao diâmetro da tubulação e os detalhes da sugestão de locação serão apresentados e detalhados nos resultados deste artigo.

Finalmente, é necessário definir a destinação final dos sedimentos captados pela armadilha. Cabe ressaltar que existe mais de uma possibilidade para isto, conforme o objetivo da implantação da armadilha desenvolvida. A seguir são apresentadas três delas, aplicáveis a este caso: Depositar os sedimentos em uma área paralela à localização da armadilha, mas que não acarrete risco de se direcionarem ao lago. Desenvolver um sistema de venda ou doação dos sedimentos para a construção civil, já que os mesmos são constituídos, em maior parte por material arenoso (UMEKI, 2012). Lançar os sedimentos recuperados no rio do Campo, logo após a barragem do lago.

Conforme se observa ao decorrer do texto, optou-se por apresentar todas as equações utilizadas na metodologia de desenvolvimento do projeto da armadilha na Tabela 1, conforme demonstrado a seguir.

Tabela 1: Equações utilizadas nas seções da Metodologia.

\begin{tabular}{|l|l|l|}
\hline Equação & Descrição & Descrição da equação \\
\hline $\mathbf{1}$ & Cálculo da vazão na captação e no vertedor & $\mathrm{Q}=1,838 \cdot(\mathrm{L}-0,20 \mathrm{~h}) \mathrm{h}^{\frac{3}{2}}$ \\
\hline $\mathbf{3}$ & Cálculo da área necessária à armadilha & $\mathrm{A}=\frac{\mathrm{Q}}{\mathrm{Vs}}$ \\
\hline & Estimativa da largura & $\mathrm{L}=\frac{\mathrm{A}}{\mathrm{b}}$ \\
\hline
\end{tabular}




\begin{tabular}{|c|c|c|}
\hline 4 & Determinação da largura final & Lfinal $=1,5 . \mathrm{L}$ \\
\hline 5 & \multirow{2}{*}{ Determinação da profundidade da armadilha } & $\mathrm{V}=\frac{\mathrm{Q}}{\mathrm{A}}$ \\
\hline 6 & & $\mathrm{~h}=\frac{\mathrm{A}}{\mathrm{b}}$ \\
\hline 7 & Capacidade de armazenamento & $\mathrm{V}=\left[\left(\frac{\mathrm{B}+\mathrm{b}}{2}\right) \cdot \mathrm{h}\right] \cdot \mathrm{L}$ \\
\hline 8 & Cálculo da perda de carga h & $\mathrm{h}=\mathrm{k}\left(\frac{\mathrm{V}^{2}}{2 \mathrm{~g}}\right)$ \\
\hline 9 & Cálculo do coeficiente de perda de carga $\mathrm{k}$ & $\mathrm{k}=\beta\left(\frac{\mathrm{s}}{\mathrm{b}}\right)^{1,33} \cdot \operatorname{sen} \alpha$ \\
\hline 10 & Determinação da área transversal interna da tubulação & $A=\frac{\pi d^{2}}{4}$ \\
\hline 11 & Cálculo da vazão na tubulação & $\mathrm{Q}=\mathrm{V} \cdot \mathrm{A}$ \\
\hline 12 & Cálculo do tempo de esvaziamento da armadilha & $\mathrm{t}=\frac{\text { Volume total }}{\text { Vazão }}$ \\
\hline
\end{tabular}

\section{RESULTADOS}

\section{Caracterização da bacia do rio do Campo}

De acordo com Umeki (2012), a área da bacia hidrográfica do rio do Campo é igual a 115,93 $\mathrm{Km}^{2}$. Assim, é possível determinar a vazão média $\left(Q_{50}\right)$ igual a $2,21 \mathrm{~m}^{3} / \mathrm{s}$ e a vazão máxima (período de retorno de 100 anos), igual a $34,37 \mathrm{~m}^{3} / \mathrm{s}$.

\section{Projeto Construtivo}

A armadilha de sedimentos deverá ser posicionada no ponto de transição do rio para o lago, ou seja, onde é feita a tomada de água. Este posicionamento é apresentado na Figura 10.

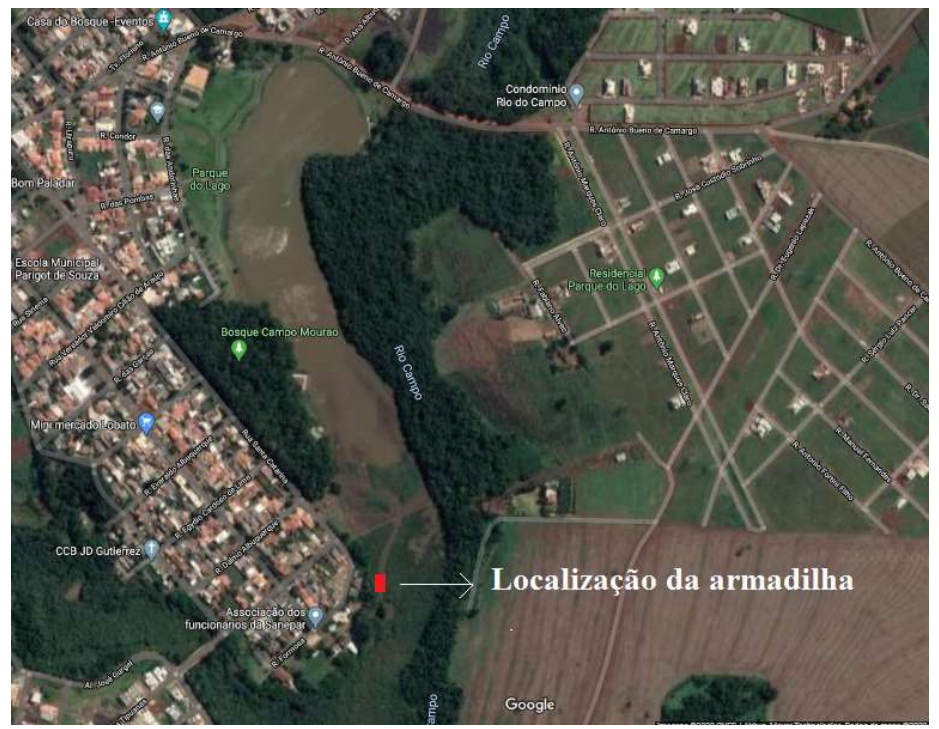

Figura 10: Posicionamento da armadilha de sedimentos Fonte: Adaptado de Google Maps (2020). 
Para o dimensionamento da captação e do vertedor da armadilha, inicialmente testou-se uma largura (L) de 3 metros e altura (h) 0,5 metros. A vazão (Q) obtida foi de 1,88 $\mathrm{m}^{3} / \mathrm{s}$ e como esta capacidade de vazão não supre a vazão média do rio de $2,21 \mathrm{~m}^{3} / \mathrm{s}$, aumentou-se a largura para 5 metros e manteve-se altura de 0,5 metros. Obteve-se, assim, vazão de 3,18 $\mathrm{m}^{3} / \mathrm{s}$, que atende a vazão média. Portanto, estabeleceu-se largura (L) de 5 metros e altura (h) de 0,5 metros para a captação e para o vertedor. A representação do detalhamento da captação de água e do vertedor após dimensionamento é apresentada na Figura 11, respectivamente.

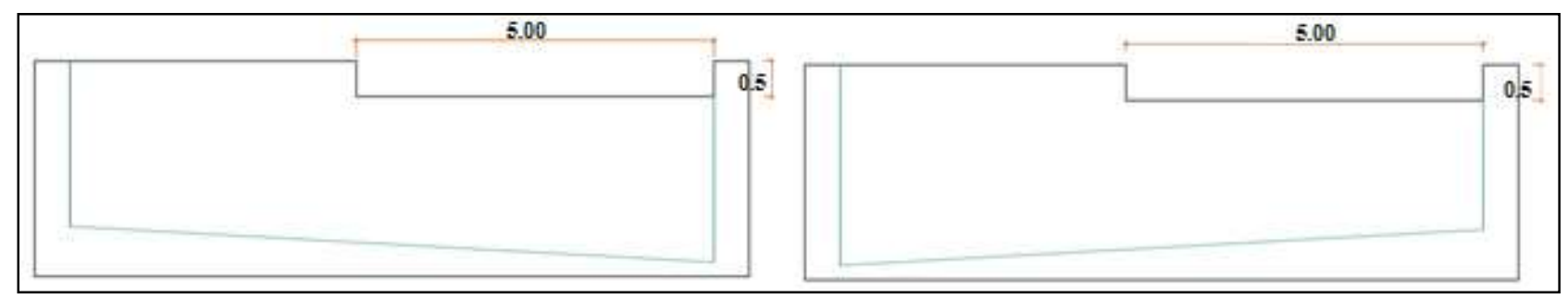

Figura 11: Detalhamento: Captação e vertedor, respectivamente.

Com relação a inclinação interna anteriormente abordada, adotou-se $\mathrm{i}=5,6 \%$, conforme apresenta a Figura 12.

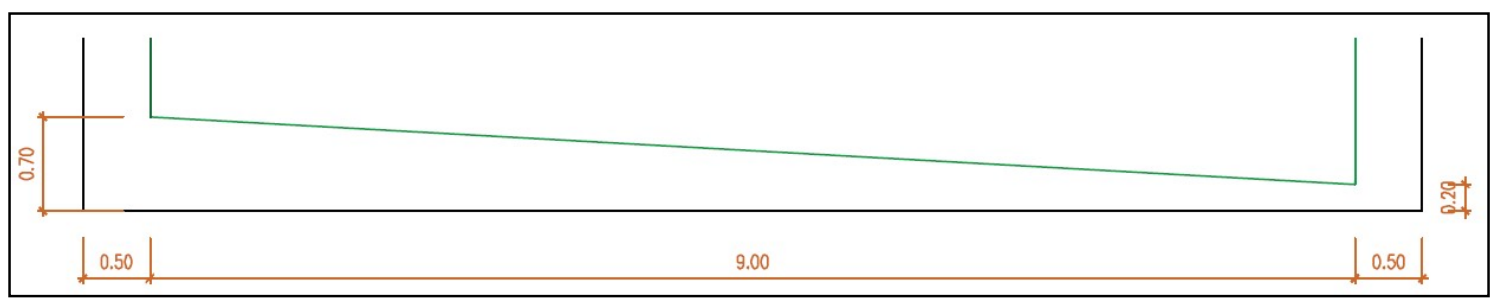

Figura 12: Detalhe da inclinação interna da armadilha de sedimentos.

Para o cálculo da área da armadilha de sedimentos foi utilizada a vazão média do rio do Campo $\left(Q_{50}\right)$ de $2,21 \mathrm{~m}^{3} / \mathrm{s}$ e velocidade crítica de sedimentação $\left(V_{\mathrm{s}}\right)$ de $0,021 \mathrm{~m} / \mathrm{s}$. O resultado da área necessária à armadilha foi de 105,19 $\mathrm{m}^{2}$. Considerou-se, de forma arbitrária, largura (b) de 8 metros e o comprimento pôde ser calculado. Obteve-se comprimento (L) igual a 11,69 m. Para compensar a turbulência na entrada e saída da armadilha, aplicou-se coeficiente de segurança de $50 \%$ no comprimento L, sendo assim, o comprimento final ( $\left.L_{\text {final }}\right)$ da armadilha foi de $17,53 \mathrm{~m}$.

Finalmente definiu-se que a armadilha de sedimentos deve possuir largura interna de $9 \mathrm{~m}$ e comprimento interno de $19 \mathrm{~m}$. Ao considerar as espessuras das paredes de 0,5 m tem-se largura total de 10 m e comprimento total de 20 m, conforme apresenta a Figura 13.

Para determinar a profundidade da armadilha foi preciso definir as dimensões da seção transversal da mesma, ou seja, a mesma largura (b) e profundidade (h). Para isto, é necessário dispor da velocidade de escoamento longitudinal (V) e da vazão $Q\left(2,21 \mathrm{~m}^{3} / \mathrm{s}\right)$. Tsutiya (2006) estabelece que a velocidade de escoamento longitudinal não deva exceder $0,30 \mathrm{~m} / \mathrm{s}$. Primeiramente foi verificada a velocidade de escoamento longitudinal (V) para uma profundidade (h) de 2 metros e a velocidade encontrada foi de 0,123 $\mathrm{m} / \mathrm{s}$. Como está velocidade é menor que $0,30 \mathrm{~m} / \mathrm{s}$, é possível utilizá-la para o dimensionamento da profundidade. Obteve-se então área transversal $(A)$ da armadilha igual a $17,96 \mathrm{~m}^{2}$ e profundidade $(\mathrm{h})$ igual a 
1,99 m. No entanto, para aumentar a capacidade da armadilha de sedimentos, conforme se justifica nas próximas seções, optou-se por adotar profundidade interna $\mathrm{h}$ de 2,30 metros. Finalmente todas as dimensões da armadilha foram definidas e são apresentadas na Figura 14.

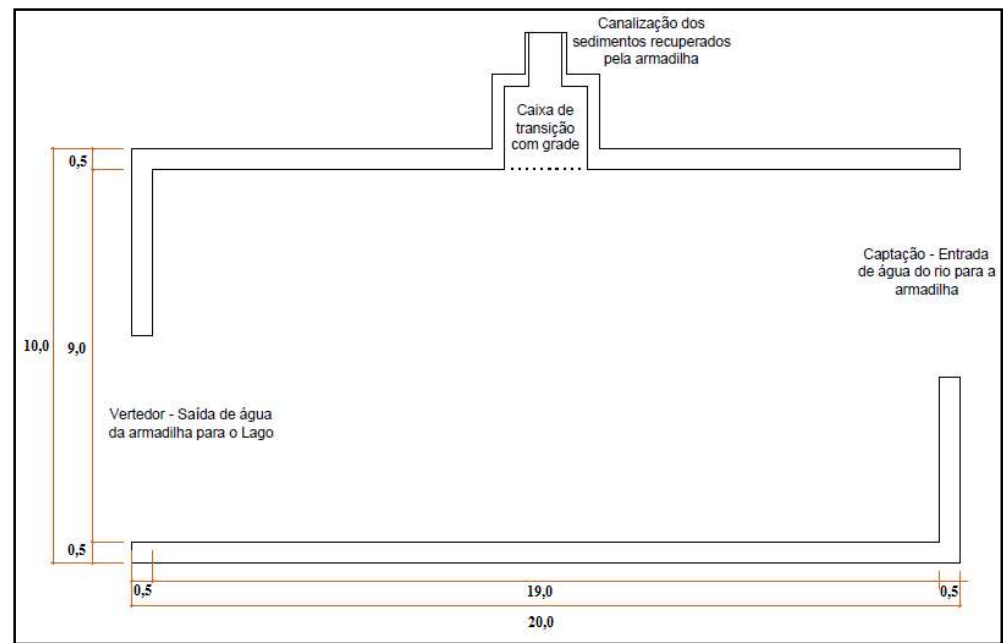

Figura 13: Largura e comprimento em planta da armadilha.

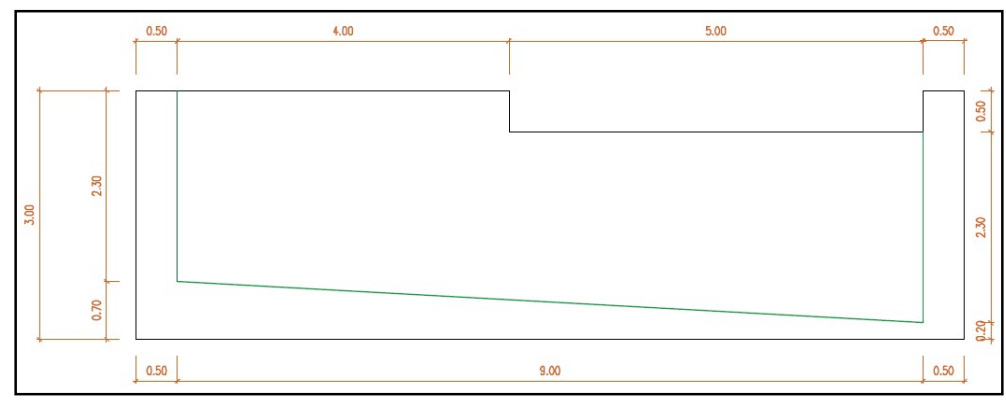

Figura 14: Medidas da armadilha em corte (vista frontal - captação).

Já é possível determinar o volume interno da armadilha de sedimentos, mas primeiramente cabe representar (em corte) seu espaço físico por meio da Figura 15.

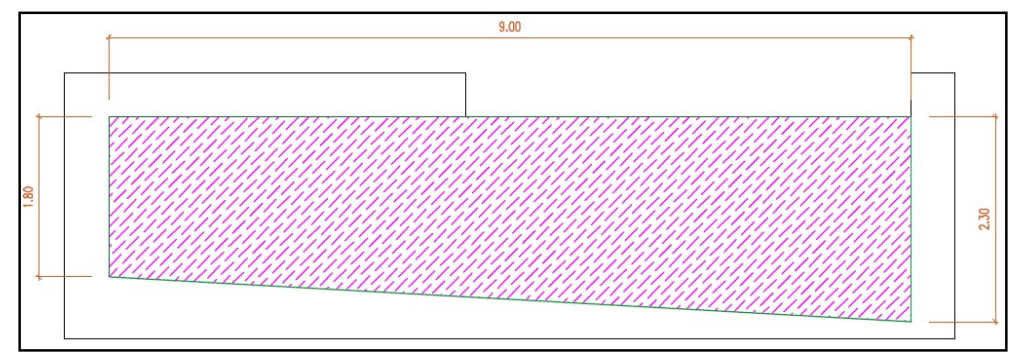

Figura 15: Valores das incógnitas para determinação do volume interno

Obtém-se assim, capacidade de armazenamento da armadilha, igual a 350,55 $\mathrm{m}^{3}$ e segundo Umeki (2012), adentra ao parque cerca de 3704,80 toneladas de sedimentos ao ano. Para complementar este dado, o autor Carvalho et al. (2000) aborda o peso específico aparente médio de depósitos de sedimentos, igual a 1,5 toneladas por metro cúbico $\left(1,5 \mathrm{ton} / \mathrm{m}^{3}\right)$.

Portanto, ao considerar eficiência de captação de 70\% à armadilha, sua capacidade de retenção é de 2593,36 toneladas de sedimentos por ano, ou $1729 \mathrm{~m}^{3}$ /ano. Tem-se, portanto a necessidade de abrir a comporta 5 vezes ao ano para esvaziamento total da armadilha, quando se considera a utilização de sua 
capacidade máxima de armazenamento. Com relação à caixa de transição, optou-se por largura (L) de 2,00 $\mathrm{m}$ e altura (h) de 1,00 m. Obteve-se, assim, capacidade de vazão igual a 3,31 $\mathrm{m}^{3} / \mathrm{s}$. O espaçamento entre barras adotado foi de $15 \mathrm{~cm}$ e optou-se por seção transversal quadrada $(3 \mathrm{~cm} \times 3 \mathrm{~cm})$ às mesmas. Os detalhes estão na Figura 16.

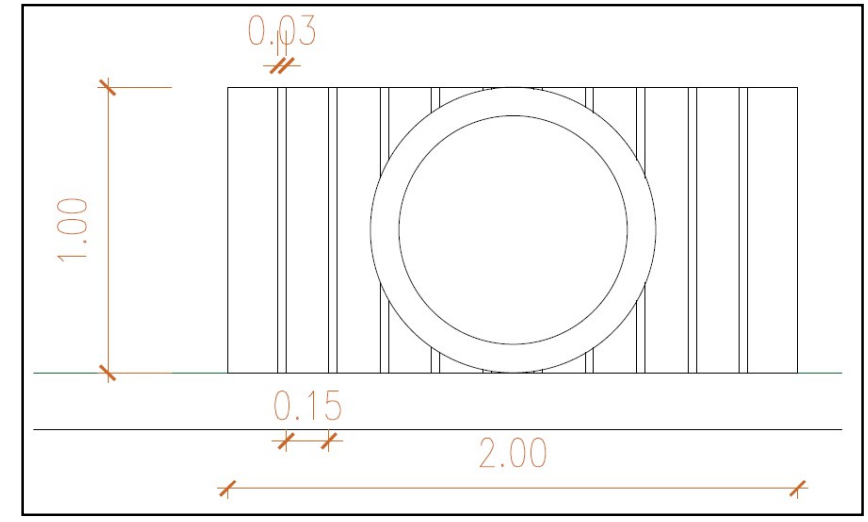

Figura 16: Medidas da caixa de transição e do gradeamento.

Obteve-se, primeiramente, velocidade média de aproximação dos depósitos (V) igual a 1,65 m/s e coeficiente de perda de carga (k) igual a 0,284 (adimensional). Como o ângulo da grade em relação a horizontal adotado é igual a $90^{\circ}$, tem-se coeficiente de perda de carga em função dos parâmetros geométricos das barras ( $\beta$ ) igual a 2,42. Assim, tem-se perda de carga (h) igual a 0,040 m gerada pela inserção do gradeamento na caixa de transição.

Como a tubulação a ser conectada a caixa de transição ocupará toda a seção transversal da mesma tem-se diâmetro externo de 1,00 m e diâmetro interno igual a 0,80 m. Assim, a área da seção transversal interna da tubulação é igual a $0,5 \mathrm{~m}^{2}$, a vazão (Q) é igual a $0,83 \mathrm{~m}^{3} / \mathrm{s}$ e o tempo necessário de esvaziamento é de 7 minutos. Os detalhes destas medidas estão apresentados na Figura 17.

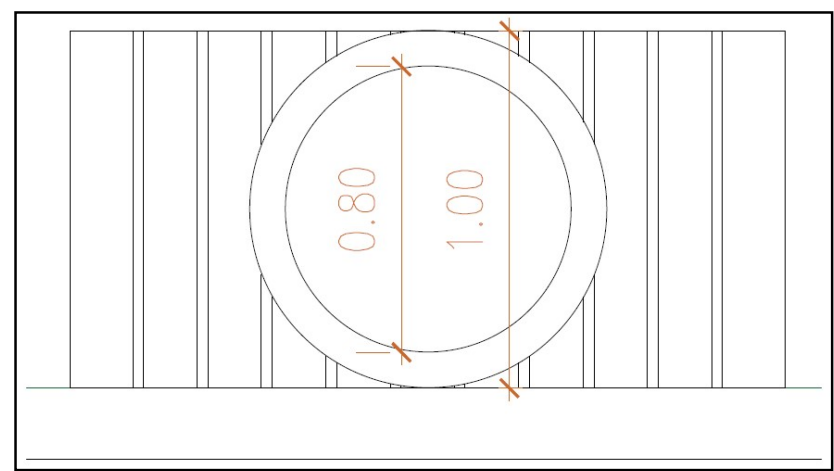

Figura 17: Diâmetros interno e externo da tubulação.

Optou-se por lançar os sedimentos recuperados pela armadilha no rio do campo, logo após a barragem do lago, conforme o que é apresentado pela Figura 18. Esta decisão se deve ao fato desta opção ser a mais 'autossustentável', ou seja, não necessitar de nenhuma intervenção humana. A figura 18 também apresenta a sugestão da locação do canal aberto em vala. A distância retilínea entre a armadilha e o ponto final de descarte dos sedimentos é de aproximadamente 500 metros e margeia o rio do Campo. 


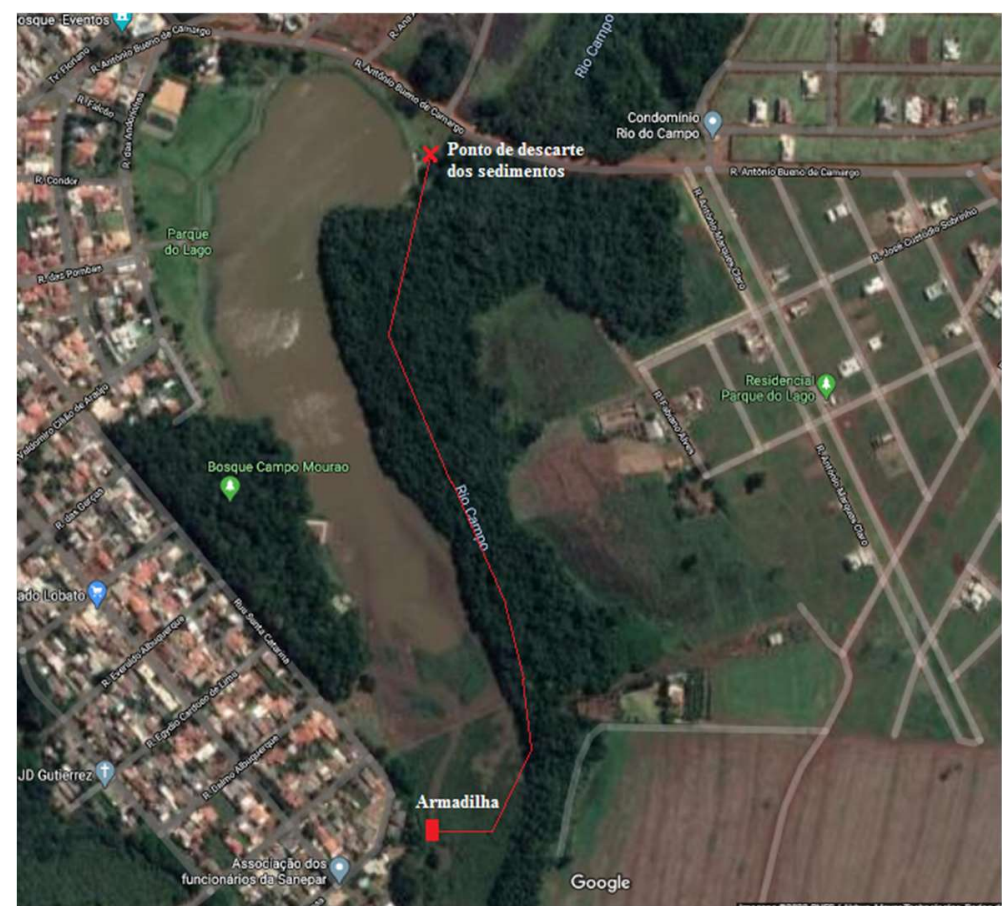

Figura 18: Locação do canal de transporte de sedimentos e ponto final de descarte. Fonte: Adaptado de Google Maps (2020).

Com o objetivo de tornar mais clara a visualização do projeto da armadilha de sedimentos, serão apresentadas algumas visualizações em três dimensões da mesma. Por meio da Figura 19 apresenta-se o projeto em três dimensões da armadilha de sedimentos com detalhamento de seu lado direito, onde se encontra a caixa de transição e a respectiva tubulação.

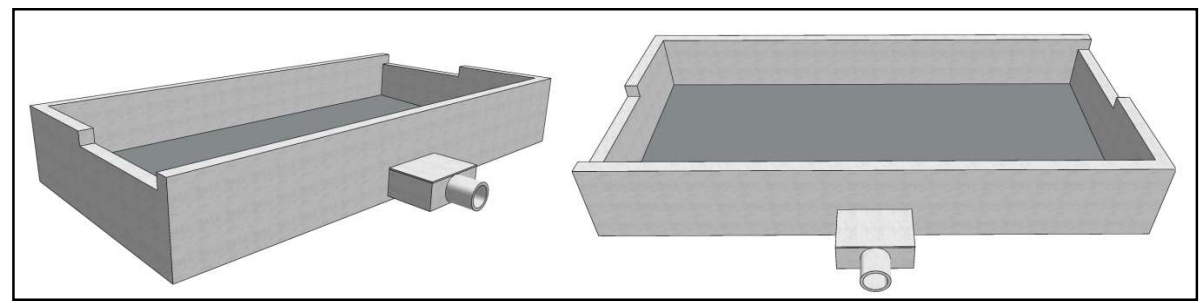

Figura 19: Projeto em três dimensões da armadilha de sedimentos - Lateral direita.

Já por meio da Figura 20 observa-se a perspectiva (em três dimensões) da lateral esquerda da armadilha de sedimentos.

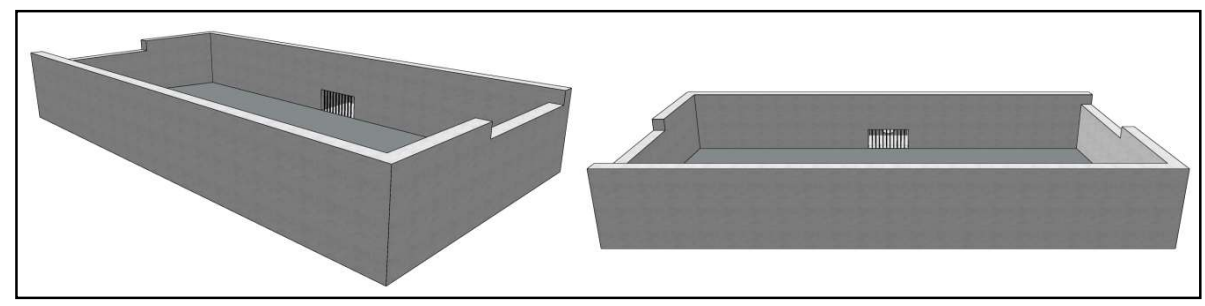

Figura 20: Projeto em três dimensões da armadilha de sedimentos - Lateral esquerda.

Finalmente, na Figura 21, apresenta-se a modelagem cotada em três dimensões do projeto da armadilha de sedimentos com o intuito de facilitar sua visualização e assimilação. 


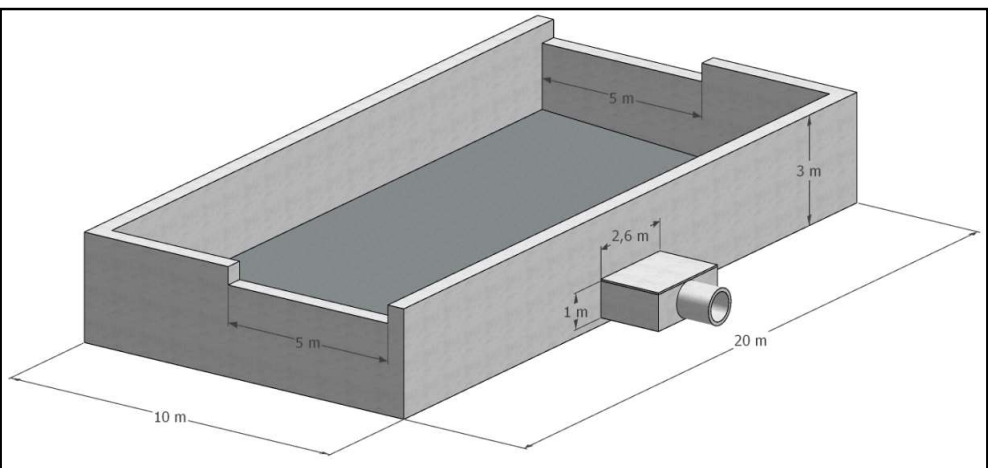

Figura 21: Projeto em três dimensões da armadilha de sedimentos cotado.

\section{DISCUSSÃO}

Foi possível promover o desenvolvimento do projeto da armadilha de sedimentos com sua implantação destinada ao lago do parque Joaquim Teodoro de Oliveira (Campo Mourão, Paraná). A obtenção de alguns resultados foi facilitada devido à existência de uma quantidade significativa de estudos que envolvem a bacia do rio do Campo. Um dos resultados encontrados na literatura foi a área da bacia do Rio do Campo, igual a 115,9279 km². Por meio desta área foi possível determinar a vazão média da bacia do Rio do Campo, de $2,21 \mathrm{~m}^{3} / \mathrm{s}$ e a vazão máxima (para um período de retorno de 100 anos) igual a $34,37 \mathrm{~m}^{3} / \mathrm{s}$.

Assim foi possível iniciar o projeto construtivo da armadilha de sedimentos. Optou-se por dispô-la no ponto de tomada de água do Rio do Campo para o lago para captar o máximo de sedimentos possível oriundo do rio. Para não atingir extravazamento da armadilha em situações de vazão média, os elementos de captação de água e vertedor foram dimensionados com medidas de 5,00 metros de largura, 0,5 metros de altura e 0,5 metros de espessura. Assim, a capacidade de vazão (Q) destes elementos é de $3,18 \mathrm{~m}^{3} / \mathrm{s}$, satisfatória, já que é maior que a vazão média $\left(Q_{50}\right)$ igual a $2,21 \mathrm{~m}^{3} / \mathrm{s}$. Também foi definida inclinação interna de 5,6\% à armadilha, apenas para induzir a deposição dos sedimentos próxima à caixa de transição.

Foram atribuídos largura, comprimento e altura de 10, 20 e 3 metros, respectivamente, à armadilha e profundidade interna de 2,30 m. Esta última é definida ao se considerar tanto a inclinação interna quanto as espessuras das paredes da armadilha. Assim, obteve-se volume interno igual a 350,55 $\mathrm{m}^{3}$. Como adentra ao parque cerca de 3704,80 toneladas de sedimentos ao ano e o peso específico médio destes é de 1,50 ton $/ \mathrm{m}^{3}$, quando se considera eficiência de captação de $70 \%$ à armadilha, a mesma é capaz de impedir que $1729 \mathrm{~m}^{3}$ de sedimentos adentrem ao lago anualmente.

Além da armadilha foram dimensionados dois elementos destinados a promover a descarga dos sedimentos retidos pela armadilha: A caixa de transição gradeada e a tubulação de descarga, já que os sedimentos serão destinados a um canal aberto e descartados em um ponto do rio do Campo localizado após a barragem. A caixa de transição com grade possui 2 metros de largura e de comprimento e 1 metro de altura, o que garante a ela capacidade de vazão de $3,31 \mathrm{~m}^{2} / \mathrm{s}$. A grade escolhida para ser implantada foi a grosseira (espaçamento de $15 \mathrm{~cm}$ ), porque o intuito é impedir que elementos grosseiros obstruam a tubulação e possui grades de seção transversal quadrada $(3 \mathrm{~cm} \times 3 \mathrm{~cm})$.

A tubulação possui diâmetro interno de $80 \mathrm{~cm}$ e externo de 1 metro, dimensionada para viabilizarse a caixa de transição. Tem capacidade de vazão de $0,83 \mathrm{~m}^{3} / \mathrm{s}$, o que permite esvaziar a armadilha de 
sedimentos em aproximadamente 7 minutos. Esta tubulação terá como destino final o canal aberto que deverá se estender desde a armadilha até o ponto final de descarte dos sedimentos, localizado no rio do Campo logo após a barragem do lago. O projeto detalhado deste canal não foi desenvolvido devido às dificuldades de obtenção de informações a respeito da declividade do local. No entanto, existem outras possibilidades para a destinação final dos sedimentos, tais como a comercialização ou doação destes sedimentos para utilização na construção civil. Para isto, sugere-se que a destinação final (ou ponto final da tubulação) seja em local amplo, licenciado ambientalmente e de fácil acesso para entrada e saída de caminhões.

\section{CONCLUSÕES}

O assoreamento é classificado como um processo natural recorrente em reservatórios e lagos, ou seja, pode ser considerado um processo inevitável caso alguma intervenção não seja implantada. Neste sentido, poucos estudos e/ou sistemas específicos foram desenvolvidos com o objetivo de tornar este processo menos agressivo. Um método paliativo bastante utilizado por prefeituras são as dragagens, no entanto são de custo elevado e não eficazes.

Ao analisar está deficiência e a necessidade do desenvolvimento de uma medida efetiva para enfrentar o problema do assoreamento de lagos e reservatórios, optou-se por desenvolver o projeto de uma armadilha de sedimentos aplicada ao lago do parque Joaquim Teodoro de Oliveira de Campo Mourão no Paraná, no entanto, isto não impede que este projeto seja adaptado e implantado em outros lagos e/ ou reservatórios assoreados.

Claramente a armadilha de sedimentos desenvolvida neste estudo deve ser enxergada como um componente de um sistema maior que deve ser projetado para combater o problema do assoreamento especificamente para cada caso, já que implantá-la em um lago ou reservatório já assoreado não vai sanar as deposições antigas de sedimentos e o comprometimento do volume do reservatório. Seria interessante, por exemplo, executar e implantar a armadilha de sedimentos na captação de água de reservatórios assoreados após a execução de dragagens, de modo a aliar uma medida paliativa a outra mais efetiva.

Finalmente, cabe dizer que os objetivos inicialmente definidos para o desenvolvimento deste estudo foram atingidos, já que foi possível estabelecer dados como a vazão da bacia do rio do Campo e a quantidade de sedimentos que adentra anualmente ao lago para, em seguida, projetar este novo sistema de captação de sedimentos e apresentá-lo em três dimensões, além de detalhar toda a sua funcionalidade, caso seja efetivado. Além disto, de forma a tornar mais completa a explanação funcional do sistema, as localizações tanto do canal aberto responsável por transportar os sedimentos captados quanto da destinação final dos mesmos puderam ser sinalizadas e apresentadas.

\section{REFERÊNCIAS}

CABRAL, J. B. P.. Estudo do processo de assoreamento em reservatórios. Revista Eletrônica Caminhos da Geografia, Uberlândia, v.6, n.14, p.62-69, 2005.

CARNEIRO, M. G.; FERREIRA, J. H. D.. Caracterização da vegetação arbórea do município de Campo Mourão/PR. In: 
SEMINÁRIO DE INICIAÇÃO CIENTÍFICA E TECNOLÓGICA DA UTFPR, 15. Anais. Cornélio Procópio: UTFPR, 2010.

CARVALHO, N. O.; FILIZOLA JÚNIOR, N. P.; SANTOS, P. M. C.; LIMA, J. E. F. W.. Guia de práticas sedimentométricas. Brasília: SIH, 2000.

PORTO, R. M.. Hidráulica básica. 4 ed. São Paulo: USP, 1999

PRETZEL, L. D.. Qualidade da água da Bacia Hidrográfica do rio do Campo: Aplicação do modelo matemático QUAL UFMG. Monografia (Bacharelado em Engenharia Ambiental) - Universidade Tecnológica Federal do Paraná, Campo Mourão, 2012.
SHEN, H. W.; LAI, J. S.. Sustain reservoir useful life by flushing sediment. International Journal of Sediment Research, Beijing, v.11, n.3, p.11-17, 1996.

SOUZA, L. B. S.. Estudo experimental e Modelagem Numérica do escoamento e do assoreamento em uma Armadilha de Sedimentos. Tese (Doutorado em Hidráulica e Saneamento) - Universidade de São Paulo, São Paulo, 2006.

TSUTIYA, M. T.. Abastecimento de Água. 3 ed. São Paulo: USP, 2006

UMEKI, K. L.. Estudos do Transporte de Sedimentos na Bacia Hidrográfica Rio do Campo, Campo Mourão/PR.

Monografia (Bacharelado em Engenharia Ambiental) Universidade Tecnológica Federal do Paraná, Campo Mourão, 2012.

A CBPC - Companhia Brasileira de Produção Científica (CNPJ: 11.221.422/0001-03) detém os direitos materiais desta publicação. Os direitos referem-se à publicação do trabalho em qualquer parte do mundo, incluindo os direitos às renovações, expansões e disseminações da contribuição, bem como outros direitos subsidiários. Todos os trabalhos publicados eletronicamente poderão posteriormente ser publicados em coletâneas impressas sob coordenação da Sustenere Publishing, da Companhia Brasileira de Produção Científica e seus parceiros autorizados. Os (as) autores (as) preservam os direitos autorais, mas não têm permissão para a publicação da contribuição em outro meio, impresso ou digital, em português ou em tradução. 